\title{
ESTIMATION OF INDICES RELATED TO PHYSICAL ACTIVITY IN UKRAINE, POLAND, AND MEMBER COUNTRIES OF ACTIVE HEALTHY KIDS GLOBAL ALLIANCE
}

original paper

(c) University School of Physical Education in Wroclaw

DOI: https://doi.org/10.5114/hm.2019.87337

\section{RYSZARD BARTOSZEWICZ ${ }^{1}$, ANDRIY BOGDANOVICH MANDYUK ${ }^{2}$, YEVHEN NIKODIMOVICH PRYSTUPA ${ }^{2}$}

${ }^{1}$ University School of Physical Education in Wrocław, Wrocław, Poland

${ }^{2}$ Lviv State University of Physical Culture, Lviv, Ukraine

\section{ABSTRACT}

Purpose. To compare the estimated indices of physical activity in Ukraine, Poland, and other countries in accordance with Active Healthy Kids Global Alliance (AHKGA) standards.

Methods. The study of schoolchildren's physical activity in Ukraine was performed in 2016 in age groups of 12-14 years ( $n=1893$, 899 boys and 994 girls) and 15-17 years ( $n=925,449$ boys and 476 girls). The results of AHKGA databases and Report Cards on Physical Activity for Children and Youth from different countries were analysed.

Results. In 2016, 38 countries from 6 continents provided reports to AHKGA. In 2018, there were 49 such countries. In accordance with the AHKGA criteria, children and adolescents' physical activity is marked from A (highest level) to $\mathrm{F}$ (lowest level). The results for Ukrainian schoolchildren pointed at the following indices of physical activity level: active play - C; organized sport and physical activity - D; active transportation - B. Poland's Report Card for Physical Activity for Children and Youth implied the following indices: organized sport and physical activity - D; active transportation - C. There were no data on active play indices in Poland. Clear patterns of the countries' economic development indices influence on the selected physical activity indices were not established.

Conclusions. According to AHKGA standards, organized sport and physical activity in Ukraine is rated D, active play - C, and active transportation - B. Organized sport and physical activity and active transportation in Poland are rated D and C, respectively. No data are available on the active play segment in Poland.

Key words: schoolchildren, adolescents, physical activity, AHKGA, active transportation, organized sport, active play

\section{Introduction}

The positive effect of physical activity on a person's health is a commonly recognized fact. Nowadays, the significance of physical activity for body formation in different age groups of children is the subject of many scientific studies around the world [1-3]. An insufficient physical activity level can lead to the development of numerous diseases and negatively affect the overall functional status of the organism [4].

Today, the physical activity of children of all ages is considered as a set of organized and free forms of activities that are carried out throughout the day [5]. The special concern of specialists is the volume of physi- cal activity among children and adolescents in their free time. The decrease in the volume of physical activity is often due to the fact that children of all ages choose inactive ways of spending their free time [5-7]. This phenomenon is also promoted by general economic development and the improvement of different countries citizens' well-being [8, 9]. Nowadays, many school learners spend their leisure time watching TV or using computers, which adds to their lack of physical activity [1]. More than half of female students did not undertake movement activity of medium or high intensity [10].

Ukraine and Poland were chosen for comparison because of the following reasons:

Correspondence address: Ryszard Bartoszewicz, University School of Physical Education, al. I.J. Paderewskiego 35, 51-612 Wrocław, Poland, e-mail: ryszard1959bar@gmail.com

Received: November 5, 2018

Accepted for publication: August 6, 2019

Citation: Bartoszewicz R, Mandyuk AB, Prystupa YN. Estimation of indices related to physical activity in Ukraine, Poland, and member countries of active healthy kids global alliance. Hum Mov. 2019;20(4):79-88; doi: https://doi.org/10.5114/ hm.2019.87337 
- the two countries have similar climate and geographic conditions;

- their population is almost the same.

However, the level of economic development of Ukraine and Poland is considerably different, which allows to determine its impact on the level of physical activity.

In 2004, in Canada, the Republic of South Africa, Kenya, and the state of Louisiana (USA), there was carried out a generalization of studies on the involvement of children and adolescents in various forms of physical activity. These data formed the basis of relevant reports called Report Cards on Physical Activity. The reports contained information on the full assessment of the current state of physical activity among children and adolescents in a given country [11]. The object of developing these documents was to establish a proper practical link between the data of scientific research and their everyday life implementation. In fact, the Report Cards on Physical Activity interpreted the relevant scientific findings for practical application in the state policy to raise the level of systematic involvement of children and young people in various forms of physical activity [12].

The publication of the first reports served as a powerful tool for influencing and stimulating the relevant social priorities in Canadian public policy and impacted on the change in many aspects of government activity, thereby contributing to enhancing the effectiveness of involving children and adolescents in systematic physical activity [13].

In 2014, an organization called Active Healthy Kids Global Alliance (AHKGA) was created. It brought together academics, experts in the field of health, and everybody interested in the point, who worked together to develop physical activity among children and adolescents around the world. The number of countries joining the respective cooperation is increasing each year. Today, their reports to the Alliance are presented by scientists from 38 countries from all the continents. All reports are based on standardized schemes that provide estimations of definite physical activity segments [14].

The present study aimed to investigate the following issues:

1. Using the methodology of AHKGA, to determine the following physical activity indices of children in Ukraine: organized sport and physical activity, active play, and active transportation.

2. To compare the data obtained with similar data from the Republic of Poland and other member countries of AHKGA.
3. To determine the influence of indices of countries' economic development on selected physical activity indices.

The following hypotheses were put forward:

1. The level of involvement of children and adolescents in certain kinds of physical activity does not depend on the geographical location of the country.

2. The country's economic development level can affect the physical activity indices of children and adolescents.

\section{Material and methods}

\section{Participants}

A sociological poll among secondary school pupils of Ukraine was conducted to solve the tasks. Two groups of schoolchildren took part in the study. The first group included schoolchildren aged 12-14 years, the second group consisted of schoolchildren aged 15-17 years. The research was carried out in general educational institutions of Lviv, Ternopil, Ivano-Frankivsk, and Khmelnytskyi.

In the group of 12-14-year-old pupils, the poll was conducted in the following secondary schools: No. 1, No. 2, No. 9, No. 34, No. 54, No. 87, No. 89 (Lviv city, 906 individuals); No. 9, No. 16, No. 20 (Ternopil city, 337 individuals); No. 5, No. 7, No. 17, No. 24 (IvanoFrankivsk, 329 individuals); No. 3, No. 19 (Khmelnytskyi city, 321 individuals).

The total number of interviewed schoolchildren aged 12-14 years was 1893, which is $4 \%$ of the totality. The number of polled boys was 899; the number of girls interviewed equalled 994. According to the sociological standards, with such a number of respondents (3\% of the general number of 10,000-15,000), the error of the study was $\pm 3 \%[15,16]$.

In the group of schoolchildren aged 15-17 years, the poll was conducted in the following secondary schools: No. 1 , No. 2 , No. 9, No. 34 , No. 54 , No. 87 , No. 89 (Lviv city, 385 individuals); No. 9, No. 16, No. 20 (Ternopil city, 190 individuals); No. 5, No. 7, No. 17, No. 24 (Ivano-Frankivsk, 149 individuals); No. 3, No. 19 (Khmelnytskyi city, 201 persons).

The total number of respondents aged 15-17 years was 925 , which makes $6 \%$ of the totality. The number of interviewed boys was 449; the number of polled girls was 476. According to the sociological standards, with such a number of respondents ( $3 \%$ of the general number of $5000-10,000$ ), the error of the study was $\pm 3 \%$ $[15,16]$. 


\section{Research instrument}

The questionnaire conducted among the secondary school pupils of Ukraine was designed with the consideration of the AHKGA recommendations, which are posted on the official site of the organization [14]. During the study, some indices of different age groups children involvement were defined and connected to physical activity. These were: active play, organized sport and physical activity, and active transportation.

The obtained data were compared with similar data from the Republic of Poland and other countries. For the comparative analysis, we used the data from published reports called Report Cards on Physical Activity for 2016. These reports are systematized in the AHKGA database. Also, the results of monitoring the level of physical activity among children and adolescents in accordance with the standards of AHKGA published in specialized scientific papers were analysed.

The data presented in the reports are evaluated on a standard scale that is common to all AHKGA member countries. The scale involves rating grades from A (the highest level) to F (the lowest level). In some cases, the relevant indices may not be defined; then, they are marked with the acronym 'INC' (incomplete data) in the report [14]. The evaluation criteria are presented in Table 1.

When comparing data from different countries, information collected on gross domestic product (GDP) per capita [17] was taken into consideration, as well as indices of life expectancy in particular countries reported by the World Health Organization (WHO) [18].

\section{Ethical approval}

The research related to human use has complied with all the relevant national regulations and institu-
Table 1. Evaluation criteria for children and adolescents' physical activity status

\begin{tabular}{cc}
\hline Grade & Reference point \\
\hline A & $81-100 \%$ \\
B & $61-80 \%$ \\
C & $41-60 \%$ \\
D & $21-40 \%$ \\
F & $0-20 \%$ \\
INC & incomplete data \\
\hline
\end{tabular}

tional policies, has followed the tenets of the Declaration of Helsinki, and has been approved by the authors' institutional review board or an equivalent committee.

\section{Informed consent}

Informed consent has been obtained from all individuals included in this study.

\section{Results}

\section{Active play}

In the generalized ranking of AHKGA, two African countries - Ghana and Kenya - received the highest marks for the active play indicator. More than $50 \%$ of Kenyan children are involved in unorganized physical activity before or after classes at school. At the same time, a specific indicator that corresponds to the $\mathrm{B}$ grade in the reports of Kenya and Ghana is not specified [19, 20].

Table 2 lists the countries with the highest grades of the involvement rate of children and adolescents in active play in accordance with AHKGA standards, GDP per capita figures (according to the International Monetary Fund's 2015 report), and life expectancy indices (according to the WHO 2016 report) [17, 18].

Table 2. Countries with the highest level of involvement of children and adolescents in active play in accordance with AHKGA standards

\begin{tabular}{lcccc}
\hline Country & Grade & Involvement level & GDP per capita (USD) & Life expectancy (years) \\
\hline Ghana & $\mathrm{B}$ & - & 1401 & 62.4 \\
Kenya & $\mathrm{B}$ & - & 1432 & 63.4 \\
The Netherlands & $\mathrm{B}$ & $70 \%$ & 44,333 & 81.9 \\
New Zealand & $\mathrm{B}-$ & - & 36,963 & 81.6 \\
Belgium & $\mathrm{C}+$ & - & 40,456 & 81.1 \\
Spain & $\mathrm{C}+$ & - & 26,327 & 82.8 \\
Finland & $\mathrm{C}$ & $52 \%$ & 42,159 & 81.1 \\
Ukraine & $\mathrm{C}$ & $50.1-51.1 \%$ & 2109 & 71.3 \\
Nigeria & $\mathrm{C}$ & - & 2758 & 61.8 \\
Wales & $\mathrm{C}$ & - & - & - \\
Poland & INC & - & - & - \\
\hline
\end{tabular}

AHKGA - Active Healthy Kids Global Alliance, GDP - gross domestic product 
R. Bartoszewicz, A. Mandyuk, Y. Prystupa, Estimation of indices related to physical activity

The list of countries in which the indicator of active play in accordance with AHKGA standards rated C was larger. It consisted of 6 countries, with the level of children's involvement in the specified physical activity segment in the range of $41-60 \%$. The highest grade for the active play indicator in this group of countries was given to Belgium and Spain (Table 2) [14, 21].

In Ukraine, among children aged $12-14$ years, 51.1\% were involved in various sports games in their free time. The indices differed by $5 \%$ between boys and girls and equalled $53.8 \%$ and $48.7 \%$, respectively.

In the group of 15-17-year-olds, the indicator of schoolchildren's involvement in active play during their free time was $50.1 \%$. Here, gender differences were much more pronounced: the indicator equalled 37.8\% for girls and $63 \%$ for boys (Figure 1).

Despite the fact that some researches provide data on the unorganized physical activity of Polish children in their free time, there are currently no clear data that would reflect their involvement level in active play [22, 23]. Given the lack of specific recommendations for active play, the indicator was graded INC [23].

\section{Organized sport and physical activity}

In accordance with the evaluated scale offered by AHKGA, the involvement level of Ukrainian children aged 12-17 years for organized sport and physical activity was estimated as D. The relevant indices in the age groups of $12-14$ and $15-17$ years equalled $33 \%$ and $32.3 \%$, respectively. The boys' indicator in both age groups significantly exceeded that for girls (Figure 2).

The analysis of additional indices such as the level of GDP per capita showed that the overall high grade of involvement in organized sport and physical activity was not related to the indices of economic development, as the list of countries with the level of this indicator estimated as D included both countries with low GDP per capita and relatively wealthy countries (Table 3) [14].

In the Republic of Poland, 18.9\% of children and adolescents aged 10-17 years are involved in organized sport and physical activity, $27.2 \%$ attend private classes related to motor activity, $30.6 \%$ perform other organized and unorganized kinds of physical activity outside the school at least once a week [23]. The last indicator was the basis for grade D.

As for the group of countries where the involvement indicator of children and adolescents for organized sport and physical activity was the highest, Denmark occupies the leading position (Table 3) [24].

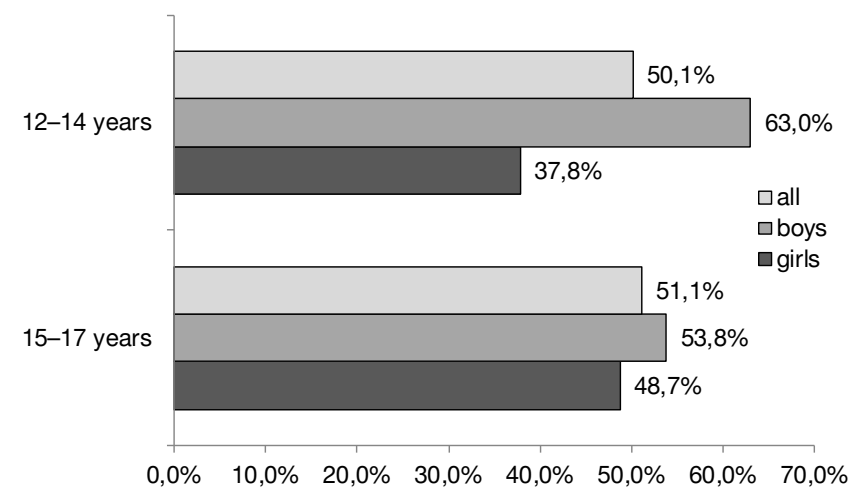

Figure 1. Level of involvement in active play among secondary school pupils in Ukraine $(n=1893$ for the group aged 12-14 years, $n=925$ for the group aged $15-17$ years)

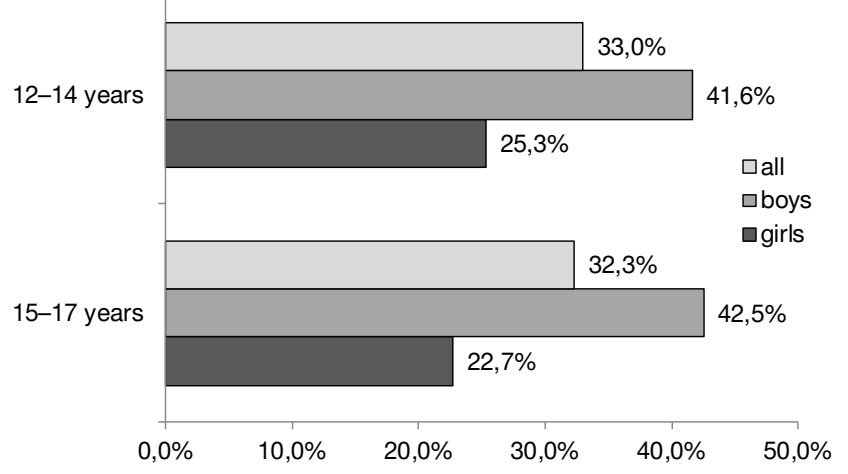

Figure 2. Level of involvement in organized sport and physical activity among secondary school pupils in Ukraine ( $n=1893$ for the group aged $12-14$ years, $n=925$ for the group aged 15-17 years)

The second place as for children and adolescents' involvement in organized sport and physical activity outside the school was taken by Sweden. The mentioned indicator was $75 \%$ in this country, and the corresponding grade was $\mathrm{B}+$. The highest level of engagement in organized kinds of sports activity was recorded among boys aged 11 years; $82 \%$ of the investigated contingent were involved in sports not less than twice a week. The lowest rate of involvement in such activities, namely $70 \%$, was recorded among girls aged 15 years [25].

In the Netherlands, as in Denmark, there was a high level of involvement in organized sports among boys and girls. The corresponding figures were $72 \%$ and $70 \%$. Interestingly, children from the age of $0-4$ years are already engaged in sports clubs in the Netherlands. The level of involvement of this contingent in 2014 was $3 \%$ [26]. 
Table 3. Countries with the highest level of involvement of children and adolescents in organized sport and physical activity

\begin{tabular}{lcccc}
\hline Country & Grade & Involvement level & GDP per capita (USD) & Life expectancy (years) \\
\hline Denmark & A & $83 \%$ & 51,424 & 80.6 \\
Sweden & B & $75 \%$ & 48,966 & 82.4 \\
The Netherlands & B & $71 \%$ & 44,333 & 81.9 \\
Spain & B & $61-78 \%$ & 26,327 & 82.8 \\
Canada & B & $76 \%$ & 43,935 & 82.2 \\
Zimbabwe & B & $67 \%$ & 1037 & 60.7 \\
Portugal & B & - & 18,984 & 81.1 \\
Australia & B & $64 \%$ & 51,642 & 82.8 \\
Slovenia & B- & $47-60 \%$ & 20,712 & 80.8 \\
New Zealand & C & $56 \%$ & 36,963 & 81.6 \\
Mexico & D & $40 \%$ & 9592 & 76.7 \\
England & D & $34 \%$ & 44,118 & 81.2 \\
Ukraine & D & $32-33 \%$ & 2109 & 71.3 \\
Poland & D & $30.6 \%$ & 12,662 & 77.5 \\
Qatar & D & $25-30 \%$ & 78,829 & 78.2 \\
Chile & D & $25 \%$ & 13,331 & 80.5 \\
\hline
\end{tabular}

GDP - gross domestic product

\section{Active transportation}

The analysis of this physical activity indicator showed that the level of involvement of Ukrainian children in active forms of transportation while overcoming the distance from home to school and vice versa corresponded to grade $B$ in accordance with the AHKGA standards. It should be noted that the active forms of movement (or transportation) denote, for the most part, walking and cycling. They also include racing, roller skating, skateboarding, scooter, and the like. Most Ukrainian schoolchildren get to school on foot. Among those aged 12-14 years, this indicator equalled $73.6 \%$. Another $3.6 \%$ of schoolchildren of this age use a bicycle. The generalized indicator for children of this age group was $77.2 \%$.

Among 15-17-year-old pupils, walking from home to school is a common matter for $75.9 \%$, and riding bicycle for $4.1 \%$. The generalized indicator equalled $80 \%$. Significant differences between genders were not found (Table 4).
As presented in Table 4, in general, 74.6\% of schoolchildren aged 12-17 years get to school on foot, and 3.8\% do it riding a bicycle. The generalized indicator for children who use active forms of getting from home to school and back was $78.4 \%$, which is a relatively high value compared with similar data from other countries.

Significant differences with regard to age characteristics of the schoolchildren were not revealed. The relevant indices remained practically unchanged, both on average and at the senior school age.

There were also no significant differences in the indices when taking into account the factor of gender. It should be noted that only among girls aged 15-17 years, there was an increase in the number of those who went to school on foot. This indicator increased by $4.3 \%$ compared with the $12-14$-year-olds.

In Poland, the percentage of children aged 11-17 years who go to school on foot is $47.4 \%$; $52.3 \%$ of children of this age return from school on foot, too. Another $5.5 \%$ of children use a bicycle to get from home to school. In general, 53-57.5\% of Polish children are

Table 4. Level of involvement in active transportation among Ukrainian children

\begin{tabular}{lcrrrrrr}
\hline \multirow{2}{*}{ Kind of transportation } & \multicolumn{2}{c}{$\begin{array}{c}\text { Age } 12-14 \text { years } \\
(n=1893, \%)\end{array}$} & \multicolumn{2}{c}{$\begin{array}{c}\text { Age } 15-17 \text { years } \\
(n=925, \%)\end{array}$} & \multicolumn{2}{c}{$\begin{array}{c}\text { Age 12-17 years } \\
(n=2818, \%)\end{array}$} & $\begin{array}{c}\text { Total } \\
(n=2818, \%)\end{array}$ \\
\cline { 2 - 6 } & \multicolumn{1}{c}{ Boys } & Girls & Boys & Girls & Boys & Girls & \\
\hline Walking & 73.9 & 73.6 & 73.7 & 77.9 & 73.8 & 75.3 & 74.6 \\
Riding a bike & 3.4 & 3.9 & 4.2 & 4 & 3.7 & 3.9 & 7.8 \\
Total & 77.3 & 77.5 & 77.9 & 81.9 & 77.5 & 79.2 & 78.4 \\
\hline
\end{tabular}


R. Bartoszewicz, A. Mandyuk, Y. Prystupa, Estimation of indices related to physical activity

Table 5. Countries where the involvement level of children and adolescents for active transportation in accordance with AHKGA standards was estimated as A or B

\begin{tabular}{lcccc}
\hline Country & Grade & Involvement level & GDP per capita (USD) & Life expectancy (years) \\
\hline The Netherlands & $\mathrm{A}$ & $91 \%$ & 44,333 & 81.9 \\
Zimbabwe & $\mathrm{A}-$ & $\geq 80 \%$ & 1037 & 60.7 \\
Ukraine & $\mathrm{B}$ & $78.4 \%$ & 2109 & 71.3 \\
Finland & $\mathrm{B}$ & $70 \%$ & 42,159 & 81.1 \\
Denmark & $\mathrm{B}$ & $68.5 \%$ & 51,424 & 80.6 \\
Hong Kong & $\mathrm{B}$ & - & 42,097 & - \\
Japan & $\mathrm{B}$ & $68-93 \%$ & 32,481 & 83.7 \\
Kenya & $\mathrm{B}$ & $60-76 \%$ & 1432 & 63.4 \\
Nigeria & $\mathrm{B}$ & $61-80 \%$ & 2758 & 61.8 \\
Thailand & $\mathrm{B}-$ & - & 5426 & 74.9 \\
Poland & $\mathrm{C}$ & $56.3-57.5 \%$ & 12,662 & 77.5 \\
\hline
\end{tabular}

AHKGA - Active Healthy Kids Global Alliance, GDP - gross domestic product

involved in active transportation, which, according to AHKGA standards, corresponds to grade C [20].

Among the European countries reporting on the physical activity of children and adolescents to AHKGA, active transportation was estimated as B also in Denmark and Finland. The statistics for all countries with the same grade are presented in Table 5 [14].

The best indices of involvement in active transportation for children of all ages were recorded in the Netherlands and Zimbabwe (Table 5) [26, 27].

As can be seen in Table 5, GDP per capita indices and life expectancy indices of the indicated countries are fundamentally different. At the same time, the number of children who use active forms of transportation when passing the distance to the educational institution is the largest in the Netherlands and Zimbabwe among the whole group of countries.

The lowest grades of the active transportation indicator were received by the United Arab Emirates (UAE) and the USA [14].

According to the annual report on the involvement of US children and adolescents in regular walking, the level of engagement in this kind of physical activity was estimated as F. This low grade is due to the fact that less than $30 \%$ of children and adolescents regularly go to and return from school on foot [28].

Interestingly, the USA and UAE are among the most economically developed countries in the world. At the same time, the increase in citizens' welfare negatively affected the physical activity of children, most of whom go to school and return home by car or school bus.

\section{Discussion}

Owing to the lack of a unified data collection algorithm and to the difficulty of correctly interpreting data, reports from 21 out of 38 countries sent to AHKGA did not contain information about the active play indicator [14].

In general, in library sources, there are no clear international recommendations for the involvement level of children of all ages in active play [21]. However, playing games is recognized as an important component of the physical activity of children and adolescents in many countries [12, 29].

Along with countries with a low GDP indicator, high grades of the active play indicator on the basis of relevant studies have been recorded in such economically developed countries as the Netherlands and New Zealand.

In Belgium, most children are involved in active play at weekends, and spring and summer are the most favourable seasons for children to play active games [21].

As it has already been noted, the highest rate of children and adolescents' involvement in organized sport and physical activity was recorded in Denmark. The most popular organizations for children and adolescents in this country are non-profit sports associations (sports clubs). The organization of sport in Denmark is rather unique, since it is primarily a system of voluntary involvement that allows the majority of the population to participate in sporting activities [24]. Almost $86 \%$ of children aged $7-15$ years are members of various sports clubs. The indicator has remained almost unchanged since 2007.

Another feature of sports management in Denmark is that the number of male and female children 
involved in the corresponding kinds of physical activity is not significantly different, which is not typical of most other countries.

The dynamics of indices of the amount of time that Danish children spend on organized activities is positive. In 1998, the number of children engaged in sports at least 6 hours per week was $22 \%$, and by 2011 the figure increased to $30 \%$ [24].

The high level of public investments in specialized infrastructure does not always contribute to an increase in the number of citizens who are systematically involved in various kinds of motor activity. In Qatar, only $25-30 \%$ of children are involved in sports during the year. A corresponding report from that country indicates that such a low indicator was recorded despite the well-developed sports infrastructure and the availability of sports facilities for citizens [30].

In England, 34\% of children aged 5-15 years are involved in organized activities outside school. Out-ofschool sports clubs account for the engagement of $27 \%$ of children of this age, while $19 \%$ of children play for some teams in their free time. Also, the report implies that sports activity is much more popular among boys. Thus, the members of the sports clubs are $35 \%$ of the boys, while among the girls this indicator is $21 \%$ [31].

By now, no clear international recommendations have been drawn up on the amount of physical activity required for children and adolescents while getting from home to school and vice versa. However, there are studies indicating that this kind of physical activity affects the total volume of physical activity among children [21, 32]. Children who go to school on foot or use other active forms of transportation are characterized by not only higher levels of motor activity, but also the best indices of somatic health [30, 32]. Unfortunately, since the beginning of the 1980s, the level of children's involvement in active forms of transportation has been declining at a very high pace. Passive forms of transportation, mainly by car, have become an alternative to active transference [32, 33].

The results in the corresponding reports from different countries are difficult to interpret for a correct comparison; the main problem is the age of children for whom the data are published. In some reports, data are collected for junior, middle, and senior schoolchildren, and in some cases data are only provided for a particular age group. In addition, individual reports take into account additional parameters, such as distance to school, season, schoolchildren's gender, etc.

In particular, data on the active transportation indicator in Finland show that $80 \%$ of children get to and from school using active ways of transportation during spring and autumn. In winter, the figure is reduced to $60 \%$ [34].

Research performed in the Kingdom of Denmark reveals that $66 \%$ of children and adolescents use active forms of getting to school, and $71 \%$ do so when they return home. As in other countries, the number of children involved in active kinds of transportation is lower at junior school age. In Denmark, for example, the corresponding indicator for children aged 6-9 years is $52.4 \%$ for getting to school and $55.4 \%$ for returning home. Among 10-15-year-olds, these indices equal $76.4 \%$ and $82.1 \%$, respectively [24].

In Japan, $28 \%$ of children aged 4-5 years are involved in active kinds of physical activity when getting to educational institutions. As many as $93 \%$ of elementary school students (aged 6-11 years) go to school on foot or ride a bike. The indicator equals $88 \%$ among 12-14-year-olds and 68\% among pupils of senior school age (15-17 years) [35].

High indices of involvement in the active transportation for elementary school pupils are unusual for most countries. However, in Japan, this trend is fairly stable. This is evidenced by data from previous studies; in particular, in 2010, the proportion of pupils of elementary school age who regularly went to school on foot amounted to $95 \%$.

Kenya and Nigeria are countries that have GDP per capita indices close to the Ukrainian one. According to statistics, $76 \%$ of schoolchildren aged $9-12$ years from the suburbs of Nairobi (capital of Kenya) go to school on foot. The corresponding indicator for schoolchildren in urban schools is $60 \%$. In general, $87 \%$ of the rural population of Kenya get to school on foot, walking or running. Among urban residents, this indicator is $58 \%$ [20].

In Nigeria, $61-80 \%$ of children and adolescents go to school on foot. The indicators of involvement in this kind of physical activity depend not only on the place of residence (rural or urban), but also on the region of the country (Northeast or Southwest) [36].

The Netherlands is a unique country whose infrastructure and citizens' lifestyle provide a very high rate of systematic involvement of children in active transportation. The point is that in the Netherlands, unlike in all other countries, the most popular form of active transfer to the educational institution among children is cycling, not walking. Overall, $80 \%$ of children aged 12-17 years get to school by bicycle more than 3 times a week and return home in the same way. Walking as a way of getting to an institution is used by only $11 \%$ of children of this age [26]. 
R. Bartoszewicz, A. Mandyuk, Y. Prystupa, Estimation of indices related to physical activity

It should be noted that approaches to the physical activity research in different countries present certain differences. Reports from various countries usually summarize research data from different groups of authors, who do not always apply defined algorithms when obtaining relevant empirical data. The development of unified approaches to research regarding some physical activity issues will allow to correctly compare the data in the future, with the consideration of economic and regional peculiarities of the countries.

We should also emphasize that a lot of countries are still not involved in the global research process of different aspects of physical activity. So, there is not enough appropriate research data.

It is obvious that the research in the field of physical activity in different countries cannot be carried out under similar conditions. In this context, we should mention such negative factors as the level of economic development, climate conditions, geographical location, political situation, etc.

\section{Conclusions}

1. In accordance with the AHKGA methodology, the physical activity indices of Ukrainian children selected for the study were assigned the following grades: active play - C (50.1-51.1\% of children aged $12-17$ years); organized sport and physical activity - D (32-33\% of children aged $12-17$ years); active transportation - B (78.4\% of children aged $12-17$ years).

2. In the Republic of Poland, the number of children involved in active play is currently not defined. The proportion of children involved in organized sport and physical activity in Poland (30.6\%) is almost the same as in Ukraine and corresponds to grade D. Indices of children's involvement in active transportation in Poland were lower than in Ukraine, amounting to $56.3-57.5 \%$ and corresponding to grade C.

3 . The highest grade (B) of the active play indicator was obtained in Ghana and Kenya. The highest rates of children's involvement in organized sport and physical activity were registered in Denmark and Sweden. The respective grades for this indicator in the countries mentioned are $\mathrm{A}$ and $\mathrm{B}+$. The highest rates of children's involvement in active transportation were established for the Netherlands and Zimbabwe. Active transportation in these countries is estimated as A.

4. As we could see from the Report Cards on Physical Activity, different indices of physical activity have the same grade in Asian, European, African, North American, and South American countries. The study did not establish clear patterns of the countries' eco- nomic development indices influence on the selected physical activity indices. Only in the case of active transportation, the lowest grades were recorded in most economically developed countries.

\section{Disclosure statement}

No author has any financial interest or received any financial benefit from this research.

\section{Conflict of interest}

The authors state no conflict of interest.

\section{References}

1. Bergier J, Niźnikowska E, Bergier B, Acs P, Salonna F, Junger J. Differences in physical activity, nutritional behaviours, and body silhouette concern among boys and girls from selected European countries. Hum Mov. 2017;18(1):19-28; doi: 10.1515/humo-2017-0009.

2. Neufer PD, Bamman MM, Muoio DM, Bouchard C, Cooper DM, Goodpaster BH, et al. Understanding the cellular and molecular mechanisms of physical activityinduced health benefits. Cell Metab. 2015;22(1):4-11; doi: 10.1016/j.cmet.2015.05.011.

3. Poitras VJ, Gray CE, Borghese MM, Carson V, Chaput JP, Janssen I, et al. Systematic review of the relationships between objectively measured physical activity and health indicators in school-aged children and youth. Appl Physiol Nutr Metab. 2016;41(6 Suppl 3):S197S239; doi: 10.1139/apnm-2015-0663.

4. Warburton DE, Bredin SS. Reflections on physical activity and health: what should we recommend? Can J Cardiol. 2016;32(4):495-504; doi: 10.1016/j.cjca.2016. 01.024 .

5. Lila A, Koussa M, Perrino T, Stoutenberg M, Prado G. The association of organized and unorganized physical activity and sedentary behavior with internalizing and externalizing symptoms in Hispanic adolescents. Child Adolesc Ment Health. 2016;21(2):109-114; doi: 10.1111/ camh.12139.

6. MacKenzie J, Brunet J, Boudreau J, Iancu HD, Bélanger M. Does proximity to physical activity infrastructures predict maintenance of organized and unorganized physical activities in youth? Prev Med Rep. 2015; 2:777-782; doi: 10.1016/j.pmedr.2015.09.005.

7. Marques A, Ekelund U, Sardinha LB. Associations between organized sports participation and objectively measured physical activity, sedentary time and weight status in youth. J Sci Med Sport. 2016;19(2):154-157; doi: 10.1016/j.jsams.2015.02.007.

8. Hills AP, Dengel DR, Lubans DR. Supporting public health priorities: recommendations for physical education and physical activity promotion in schools. Progr Cardiovasc Dis. 2015;57(4):368-374; doi: 10.1016/j. pcad.2014.09.010.

9. Sarcona A, Kovacs L, Wright J, Williams C. Differences in eating behavior, physical activity, and health-related 
lifestyle choices between users and nonusers of mobile health apps. Am J Health Educ. 2017;48(5):298-305; doi: 10.1080/19325037.2017.1335630.

10. Junger J, Kačúr P, Tlučáková L, Čech P, Bebčáková V. Physical activity of female students in secondary schools in the context of physical activity recommendations fulfilment. Hum Mov. 2017;18(3):67-73; doi: 10.1515/ humo-2017-0025.

11. Research Work Group for Ireland's Report Card on Physical Activity in Children and Youth. The 2016 Ireland North and South Report Card on Physical Activity for Children and Youth. 2016. Available from: http:// www.thehealthwell.info/sites/default/files/documents/TreetopStudio_Child_Advocacy_Document_ FINAL.pdf.

12. Tremblay MS, Gray CE, Akinroye K, Harrington DM, Katzmarzyk PT, Lambert EV, et al. Physical activity of children: a global matrix of grades comparing 15 countries. J Phys Act Health. 2014;11(Suppl 1):S113-S125; doi: 10.1123/jpah.2014-0177.

13. Tremblay MS, Barnes JD, Cowie Bonne J. Impact of the Active Healthy Kids Canada report card: a 10-year analysis. J Phys Act Health. 2014;11(Suppl 1):S3-S20; doi: 10.1123/jpah.2014-0167.

14. The global matrix 2.0 on physical activity for children and youth. Released on November $16^{\text {th }}, 2016$ at the International Congress on Physical Activity and Public Health in Bangkok, Thailand. Available from: https:// www.activehealthykids.org/global-matrix/2-0/.

15. Paniotto V, Harchenko N. Methods of polls. Kyiv: KyivMohyla Academy; 2017.

16. Bailey KD. Methods of social research. New York: Simon and Schuster; 2008.

17. International Monetary Fund. World economic outlook databases. Available from: http://www.imf.org/external/ ns/cs.aspx?id=28.

18. World health statistics 2016: monitoring health for the SDGs, sustainable development goals. Geneva: World Health Organization; 2016.

19. Ocansey R, Aryeetey R, Sofo S, Nazzar A, Delali M, Pambo P, et al. Results from Ghana's 2016 Report Card on Physical Activity for Children and Youth. J Phys Act Health. 2016;13(11 Suppl 2):S165-S168; doi: 10.1123/ jpah.2016-0272.

20. Onywera VO, Muthuri SK, Wachira L-JM, Kyallo F, Mang'eni RO, Bukhala P, et al. Kenya's 2016 Report Card on Physical Activity and Body Weight of Children and Youth. Healthy Active Kids Kenya. 2016. Available from: https:/www.activehealthykids.org/wp-content/ uploads/2016/11/kenya-report-card-long-form-2016.pdf.

21. Wijtzes AI, Verloigne M, Mouton A, Cloes M, De Ridder KAA, Cardon G, et al. The 2016 Belgium Report Card on Physical Activity for Children and Youth. Leuven: KU Leuven; 2016.

22. Lubowiecki-Vikuk AP, Biernat E. Organized and unorganized forms of physical activity in leisure time among junior high school students in relation to individual and socio-environmental factors [in Polish]. Probl Hig Epidemiol. 2015;96(2):448-457.

23. Zembura P, Goldys A, Nalecz H. Results from Poland's 2016 Report Card on Physical Activity for Children and Youth. J Phys Act Health. 2016;13(11 Suppl 2):S237S241; doi: 10.1123/jpah.2016-0386.

24. Larsen LR, Troelsen J, Kirkegaard KL, Christensen B, Riiskjær S, Krølner R, et al. The Danish Physical Activity Report Card for Children and Youth. Odense: Research and Innovation Centre for Human Movement and Learning, University of Southern Denmark \& University College Lillebaelt; 2017. Available from: https://www. activehealthykids.org/wp-content/uploads/2016/11/ denmark-report-card-long-form-2017.pdf.

25. Nyström CD, Ehrenblad B, Eneroth H, Eriksson U, Friberg M, Hagsrtömer M, et al.. Active Healthy Kids Sweden 2016 on physical activity for children and youth. 2016. Available from: https://www.activehealthykids. org/wp-content/uploads/2016/11/sweden-reportcard-long-form-2016.pdf.

26. Takken T, Burghard M, Knitel K, van Oost I. Dutch 2016 Report Card on Physical Activity for Children and Youth. Sport Society; 2016. Available from: https://www. activehealthykids.org/wp-content/uploads/2016/11/ netherlands-report-card-long-form-2016.pdf.

27. The 2016 Zimbabwe Report Card on the Physical Activity for Children and Youth. Active Healthy Kids Zimbabwe; 2016.

28. The 2017 United States Report Card on Walking and Walkable Communities. National Physical Activity Plan; 2017. Available from: https://physicalactivityplan.org/ projects/walking/Walking-report-card-FINAL.pdf.

29. Okely T, Salmon J, Vella S, Cliff D, Timperio A, Tremblay M, et al. A systematic review to inform the Australian sedentary behaviour guidelines for children and young people. Commonwealth of Australia; 2013. Available from: https://www1.health.gov.au/internet/main/ publishing.nsf/Content/3768EA4DC0BF11D0CA25 7BF0001ED77E/\$File/SR-ASBGCYP.pdf.

30. Qatar Active Healthy Kids Report Card. Available from: https://www.activehealthykids.org/wp-content/uploads/2016/11/qatar-report-card-short-form-2016.pdf.

31. England Report Card 2016 Active Travel. Available from: https://create.piktochart.com/output/11996197 -england-report-card-2016_active-travel.

32. Faulkner GE, Buliung RN, Flora PK, Fusco C. Active school transport, physical activity levels and body weight of children and youth: a systematic review. Prev Med. 2009;48(1):3-8; doi: 10.1016/j.ypmed.2008.10.017.

33. Central Statistics Office. Census 2011 Profile 10 Door to Door - Commuting in Ireland. Available from: http:// www.cso.ie/en/census/census2011reports/census2011 profile10doortodoorcommutinginireland/.

34. Finland's Report Card 2016. Physical Activity for Children and Youth. Jyväskylä: LIKES Research Centre for Physical Activity and Health; 2016. Available from: 


\section{HUMAN MOVEMENT}

R. Bartoszewicz, A. Mandyuk, Y. Prystupa, Estimation of indices related to physical activity

https://www.activehealthykids.org/wp-content/uploads/2016/11/finland-report-card-long-form-2016.pdf.

35. The 2016 Japan Report Card on Physical Activity for Children and Youth. 2016. Available from: https://www. activehealthykids.org/wp-content/uploads/2016/11/ japan-report-card-long-form-2016.pdf.

36. 2016 Nigerian Report Card on Physical Activity for Children and Youth. Lagos: Nigerian Heart Foundation; 2016. Available from: http://www.nigerianheart.org/images/ 2016\%20Nigerian\%20Report\%20Card\%20on $\% 20$ Physical\%20Activity\%20for\%20Children\%20and\% 20Youth.pdf. 